$105.8^{\circ}$. On calling in the evening her temperature was found to have fallen to $103 \cdot 4^{\circ}$, but I repeated the douche of iodine. The temperature on the next morning was $102 \cdot 4^{\circ}$ and the patient was found to be covered with a typical scarlatinal rash and she complained of sore-throat. My father (Dr. Ivor Murray), whom I called in, confirmed my diagnosis and notified scarlet fever. On making inquiries I learnt that two children of the previous tenant of the house had had scarlet fever there in the previous October; the patient and her husband came into the house in November. This was the only clue to contagion which I could get, as the patient had not been near any scarlet fever cases and I had not myself seen any for six months previously. This, I think, points to the indefinite incubation period of scarlet fever in pregnant women. The baby also took the infection, but both mother and child made uninterrupted recoveries, both desquamating freely.

CASE 2.-A sister-in-law of the above patient who was in daily expectation of being confined and who lived next door had, of course, seen her sister and the baby before I had any suspicion of anything being wrong, but when the tomperature of the first patient rose I forbade her sister-in-law to enter the house, and at the confinement of the latter on June 5th I took every precaution and was careful to put on fresh clothes. On June 8th, however, the patient's temperature ran up to $104^{\circ} \mathrm{F}$., and she had a strawberry tongue and sore-throat, but there was no definite rash. Knowing that she had been exposed to contagion I treated her as for scarlet fever. In spite of diaphoretics, quinine, Warburg's tincture, \&c., her temperature oscillated between $101^{\circ}$ and $104^{\circ}$ for fourteen days, when it went down to $99^{\circ}$. Owing to sleepless nights I had given trional ( $20 \mathrm{gr}$.) with good result, but on the $23 \mathrm{rd}$ I found that she had taken a violent dislike to nursing her baby and to her husband and that she fancied herself to be a feather and that she would blow away. On the 25th she complained of her left arm being swollen and on examination I found a hard lump in the axilla. I wrapped the arm in wool and kept her quiet, but it swelled to twice its size till under massage it gradually decreased. Her urine contained a slight amount of albumin and her legs were slightly swollen, but as she recovered strength her urine became normal. She desquamated very slightly. The mania lasted about a fortnight and she is now as strong and well as ever she was. This case I think interesting because of the number of complications which had to be contended against.

Scarborough.

\section{A NOTE ON AMPUTATION FOR CHARCOT'S} JOINT DISEASE.

By F. A. Southam, M.B. Oxon., F.R.O.S. Erg, SURGEON TO THB MANCHESTER ROYAL INFIRMARY ; LECTURER ON OPERA'TVE SURGERY, OWENS COLLEGE.

ABOUT six years ago a case of Charcot's jcint disease came under my care in which the ankle-joint had become so completely disorganised that the foot was displaced upwards and outwards, the internal malleolus projecting prominently through an opening in the skin; in fact, the appearance was not unlike that met with in an unreduced compound Pott's fracture. Removal of the foot was the obvious treatment, but in the absence of any definite information on the question of amputation in patients suffering from Charcot's joint disease, and, bearing in mind the unsatisfactory result which often follow amputation for perforating ulcer in tabetic subjects, I was hesitating somewhat as to the advisability of adopting this course, when a short article by Mr. Jonathan Hutchinson, published a few months pre viously in the Archives of Surgery, ${ }^{1}$ attracted my notice. Mr. Hutchinson wrote as follows: "I have recently had an opportunity of observing the process of repair after amputation in a state of adranced locomotor ataxy. It may be of interest to record the result since, owing to absence of any experience on the point, I felt some misgivings in recommending the measure." Details were then given of the performance of Teale's amputation in a middle-aged subject who for ten years had suffered from locomotor ataxy accompanied by perforating ulcer and disease of the bones of the foot and ankle-joint.

1 Archives of Surgery, Oct. 1891, p. 137.
The result of the operation was extremely satisfactory, the patient recovering with a sound stump, which was afterwards fitted with an artificial limb and bore pressure well.

Encouraged by Mr. Hutchinson's success I advised my patient, a male, aged forty-nine years, to submit to amputation of the leg below the knee-joint, and to this he readily consented, being anxious to be rid of the foot, which, though it caused him no pain, had become a great inconvenience to him. Since then I have performed the same operation in three other patients, all males between forty and fifty years of age, for a similar condition, the ankle-joint being affected in one case and the tarsal joints in the other two. In all four patients the result has been most satisfactory, the stumps healing quickly without suppuration and without any tendency to sloughing of the soft tissues or necrosis of the end of the bone, as might have been expected from the nervous origin of the disease.

It is somewhat strange that in most works on surgery little or no reference is made to the question of operation in cases of locomotor ataxy when a joint has become completely disorganised. In a recent text-book the following paragraph, however, appears: "In the later stages, where the joint is entirely disorganised, some form of fixed apparatus may be applied to render the limb more useful, since no operative treatment can be undertaken." 2 A similar opinion is expressed in one of the most recent German works on nervous diseases, for it is there stated that though the joint affections may require some mechanical support surgical treatment is seldom necessary, operative interference being avoided by most surgeons. ${ }^{3}$

Manchester.

\section{NOTES ON A CASE OF PERSISTENCE OF HYMEN ; NON-RUPTURE.}

By N. Cullinan, M.D. Brux.

THE following case having come under my notice may be of interest to the readers of THE LANCET from a medicolegal point of view as well as on account of the obstruction which may be caused during the second stage of labour.

On March 13th, 1898, I was called to attend a primipara, aged twenty-five years. On making my visit and questioning the midwife I found that the patient had been in labour for nine hours, the pains then recurring about every seven minutes. On attempting to make a vaginal examination $\mathbf{I}$ found that an obstruction existed and the parts were tender to the touch, which latter sensation lasted a considerable time. Having determined the position of the fœtus by an abdominal examination I resolved to await results. The labour progressed naturally until a fulness could be noticed in the perineum. A visual examination. now confirmed the conclusion which I had previously arrived at; the membrane was intact except for a small opening which would allow the escape of the menstrual fluid, situated in the antero-posterior line about one-third from the anterior and two-thirds from the posterior edge of the vaginal opening, the aperture being of suffcient size to admit an ordinary slate-pencil. The clitoris was of abnormal length and sensitive. On attempting to enlarge the opening in the hymen with the tip of the little finger the patient complained of intense pain and I decided to desist. I then used a hernia knife, making a. crucial incision, and the succeeding pain caused the protrusion of the membranes well into the opening made. After making a vaginal examination and allowing the liquor amnii to escape the labour terminated naturally, no laceration taking place. The patient made a good recovery.

The points of interest in this case are as follow: (1) the non-rupture of the membrane although the patient had been married for eleven months ; (2) the membrane itself was of a fibro-elastic consistence and extremely dense; (3) the small opening allowing impregnation to take place; (4) the abnormal sensitiveness of the parts; (5) an unusually large clitoris; and (6) the obstruction caused during the second stage of labour with the amount of force necessary to cause rupture. From a medico-legal point of view cases of this sort are of much importance showing that impregnation can take place withont rupture of the hymen, that the presence of the membrane is not a positive proof

2 Rose and Carless: A Manual of Surgery, p. 585.

3 Oppenheim: Lehrbuch der Nervenkrankheiten, vol. ii., p. 145. 
of virginity, and therefore it behoves a medical witness to be careful in giving an opinion, for if he swears that a woman is a rirgin and later she turns out to be pregnant he may involve himself in legal proceedings as well as perhaps the loss of his reputation. On the other hand, the absence of the hymen does not prove that defloration has taken place. Such a condition may exist from ulceration, masturbation. \&c.

Pontymister, Monmouthshire.

\section{NOTE ON STAINING THE CAPSULES OF PNEUMO- COCCUS AND OF THE BACILLUS OF FRIEDLÄNDER. \\ BY ALFRED MACCONKEY.}

(From the Bacteriological Laboratory of Guy's Hospital.)

RIBBERT's observation that dahlia is useful for staining the capsules of pneumococcus has not met with the attention it deserves, as there are very few references to it in the textbooks. Dahlia stains the cocci well and their capsules faintly. Bleu de Roux (dahlia with methyl green) gives a better result when slightly warmed; and the addition of fuchsin effects a still further improvement. The following combination gives a clear image which photographs well: dahlia, 0.5 gramme methyl green ( 00 crystal), 1.5 gramme; saturated alcoholic solution of fuchsin, 10 c.c.; distilled water to 200 c.c. The dahlia and methyl green are rubbed up in a mortar with part of the water until dissolved, then the fuchsin is added, and finally the rest of the water.

Staining.-Prepare the film in the usual way. Flood the cover slip with the stain and hold over the flame until steam begins to rise. Then place aside for about five minutes, wash in water, dry, and mount in xylol balsam. N.B.- If the film is treated with acetic acid before staining the result is not so good.

This serves as a good general stain and gives good results with the bacillus typhi abdominalis, bacillus coli communis, and especially with the Klebs-Löfler bacillus.

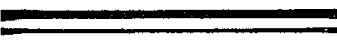 \\ A a thtirror \\ 0 T}

\section{HOSPITAL PRACTICE, BRITISH AND FOREIGN.}

Nulla autem est alia pro certo noscendi via, nisi quamplurimas et morborum et dissectionum historias, tum aliorum tum proprias collectas habere, et inter se comparare.-MokgaGNI De Sed. et Caus. Morb., lib. iv. Procmium.

\section{UNIVERSITY COLLEGE HOSPITAL.}

A CASE OF IYTUSSUSCEPTION TREATED BY LAPAROTOMY; RAPID RECOVERY.

\section{(Under the care of Mr. RICKMAN J. GodLEE.)}

WE have recently ${ }^{3}$ published cases demonstrating the value of early operation in intussusception, but the importance of adopting this method of treatment could not be more satisfactorily demonstrated than in the case reported below. The early age of the patient and the severity of the symptoms would soon have led to a fatal termination, and the difficulty with which the bowel was reduced by manipulation renders it impossible to believe that any form of injection or inflation could have effected the reduction. But inflation has dangers of its own : it has led to rupture, it may appear to succeed though the bowel is still tightly grasped, and by its use very valuable time is lost. For these reasons, and in view of the results obtained by laparotomy in many cases, it can now hardly be maintained that inflation is justifiable, except in cases where the parents refuse to allow a cutting operation. In Mr. Godlee's case the patient was only six months old, and though recovery has been recorded in several instances at an earlier age, yet it is noteworthy how rapidly the child recovered, for he was discharged perfectly well on the seventh day. For the notes

$\leq$ THE LAXceT, July 30th, 1898, and August 20th, 1898. of the case we are indebted to Mr. Montague Dixon, house surgeon.

A male infant, aged six months, was taken by his mother to the out-patient department of University College Hospital at midnight on Sept. 28th, 1898. The history given by the mother was that at six o'clock that evening the child vomited and that the vomiting was repeated at intervals until about 10.15 P.M., when he passed "some blood and slime from the back passage." He had been crying a good deal and had been restless, drawing the legs up and appearing to be in pain. The infant was doubly ruptured, was breastfed, and had had no previous illness. On examination he was seen to be a fine fat child. He was pale and seemed to be in pain. The knees were drawn up and there was evidently abdominal pain. The pulse was small and rapid. On palpation of the abdomen some tenderness was evident and the child showed his resentment by crying. Passing from the right side just below the costal margin to the epigastrium a sausage-shaped, curved tumour was felt characteristic of an intussusception. It moved with respiration, and palpation of it caused more screaming than palpation of the rest of the abdomen. Rectal examination revealed nothing. The abdomen was cleansed and disinfected and the child's limbs and chest were bandaged in wool. Chloro. form was administered and the abdomen was opened by a longitudinal incision about $2 \mathrm{in}$. in length just above the umbilicus and a little to one side of the linea alba. On drawing out the transverse colon a large intussusception was seen. The greater part of this was very easily and rapidly reduced by the ordinary manipulation, but the reduction of the last part was difficult. Of this last part the lower few inches of the ileam and the first portion of the ascending colon with the cæcum formed the intussusceptum, while the remainder of the ascending colon constituted the intussuscipiens. On firm pressure no-effect was produced for a moment, when suddenly the reduction began to be effected and the portion of large intestine forming the intussusceptum shot out and became the intussuscipiens, leaving therefore only the lower few inches of the ileum as intussusceptum. On continued manipulation this also was reduced, completing the reduction. The portion of ileum which had been invaginated was remarkably stiff and inelastic owing to exudation into its substance, and remained out of shape while under observation, forming a sort flat, oval tumour about 2 in. long by 1 in. wide. The whole bowel was, however, in good condition, the circulation throughout being maintained. The appendix was found to be quite normal and not even congested. The case was therefore of the ileo-colic variety. On the next day (Sept. 29th) the patient was doing: splendidly. The mother continued to suckle him. He had romited twice during the night. The temperature was $100.8^{\circ} \mathrm{F}$. and the pulse was 168. No flatus had been noticed. At night the child vomited once and passed a stool containing a little blood and mucus. The stool was not green but was darker than normal and rather watery. The temperature never rose again as high as $100 \cdot 8^{\circ}$ during recovery. The patient was discharged on Oct. 4th, having been in hospital six days, and he had recovered completely from his trouble.

Remarks by Mr. GoDLEE.-The case demonstrates the advantage of early operation. Had inflation been tried the modification in the shape of the tumour would have suggested that reduction had been accomplished; but the operation showed that this was absolutely impossible. It was difficult to effect even at this early period after the onset of symptoms, and a few hours' delay would have probably rendered excision of part of the gut necessary.

\section{SALFORD ROYAL HOSPITAL.}

A CASE OF ACUTE ILEO-CACAL INTUSSUSCEPTION; LAPAROTOMY AND REDUCTION ; NECROPSY.

\section{(Under the care of Mr. J. H. RAY.)}

THE following case is chiefly remarkable for the great acuteness of the symptoms; the intussusception commenced apparently at three o'clock in the morning, and the child died about twenty-four hours later. The younger the patient as a rule the more serere are the symptoms and the greater the probability of a fatal issue. This is due to two causes: in the first place, young children stand very badly the shock 